\title{
AMEG: the new SETAC advisory group on aquatic macrophyte ecotoxicology
}

\author{
Gertie Arts • Jo Davies • Michael Dobbs • Peter Ebke • Mark Hanson • Udo Hommen • \\ Katja Knauer • Stefania Loutseti • Lorraine Maltby • Silvia Mohr • Angela Poovey • \\ Véronique Poulsen
}

Received: 17 December 2009/Accepted: 8 February 2010 / Published online: 1 March 2010

(C) The Author(s) 2010. This article is published with open access at Springerlink.com

\begin{abstract}
Introduction and background Primary producers play critical structural and functional roles in aquatic ecosystems; therefore, it is imperative that the potential risks of toxicants to aquatic plants are adequately assessed in the risk assessment of chemicals. The standard required macrophyte test species is the floating (non-sediment-rooted) duckweed Lemna spp. This macrophyte species might not be representative of all floating, rooted, emergent, and submerged macrophyte species because of differences in the duration and mode of exposure; sensitivity to the
\end{abstract}

Responsible editor: Henner Hollert

G. Arts $(\bowtie)$

Alterra WUR,

P.O. Box 47, 6700 AA Wageningen, The Netherlands

e-mail: Gertie.Arts@wur.nl

J. Davies

Jealott's Hill International Research Centre, Syngenta,

Bracknell, Berkshire RG 42 6EY, UK

\section{Dobbs}

Bayer CropScience LP,

2 T.W. Alexander Drive, P.O. Box 12014, Research Triangle Park, NC 27709, USA

\section{P. Ebke}

Mesocosm GmbH,

Neu-Ulrichstein 5,

35315 Homberg (Ohm), Germany

\section{Hanson}

University of Manitoba,

Winnipeg, MB R3T 2N2, Canada

U. Hommen

Fraunhofer IME,

Auf dem Aberg 1,

57392 Schmallenberg, Germany specific toxic mode of action of the chemical; and speciesspecific traits (e.g., duckweed's very short generation time). Discussion and perspectives These topics were addressed during the workshop entitled "Aquatic Macrophyte Risk Assessment for Pesticides" (AMRAP) where a risk assessment scheme for aquatic macrophytes was proposed. Four working groups evolved from this workshop and were charged with the task of developing Tier 1 and higher-tier aquatic macrophyte risk assessment procedures. Subsequently, a SETAC Advisory Group, the Macrophyte Ecotoxicology Group (AMEG) was formed as an umbrella organization for

\section{K. Knauer}

Federal Office for Agriculture,

Mattenhofstr. 5,

CH-3003 Bern, Switzerland

S. Loutseti

Du Pont Hellas S.A.

12, Solomou St., Halandri,

15232 Athens, Greece

L. Maltby

The University of Sheffield,

Sheffield S10 2TN, UK

S. Mohr

Federal Environment Agency,

Schichauweg 58,

12307 Berlin, Germany

A. Poovey

US Army Corps of Engineer Research and Development Center, 3909 Halls Ferry Rd,

Vicksburg, MS 39180, USA

V. Poulsen

AFSSA-DiVE-Ecotoxicology and Environmental Fate Unit,

10, Rue Pierre Curie,

94704 Maisons-Alfort, France 
various macrophyte working groups. The purpose of AMEG is to provide scientifically based guidance in all aspects of aquatic macrophyte testing in the laboratory and field, including prospective as well as retrospective risk assessments for chemicals. As AMEG expands, it will begin to address new topics including bioremediation and sustainable management of aquatic macrophytes in the context of ecosystem services.

Keywords Aquatic macrophytes · Risk assessment · Tools · Guidance $\cdot$ Chemicals

\section{Background}

Aquatic macrophytes are important primary producers of aquatic ecosystems that must be protected from adverse chemical effects in order to maintain important ecosystem structure and functions. Macrophytes fulfil several critical functions in aquatic ecosystems including conversion of solar energy and carbon dioxide into organic matter; production of oxygen; sequestration of carbon dioxide; cycling and retention of nutrients; stabilization of sediments; and provision of food and habitat resources for aquatic fauna (Wetzel 2001). Thus, aquatic macrophytes, and the ecosystem services that they provide, must be protected on a local and global basis.

Currently, the only aquatic macrophyte used in risk assessment of plant protection products (e.g., herbicides and plant growth regulators) under the European Regulation (EC 2009) is the standardized growth inhibition test with duckweed (Lemna spp.; EC 1997). Additional data with other aquatic plant species may be required on a case-bycase basis (EC 2002). In other regulatory frameworks, macrophytes are not obligatory in the risk assessment, e.g., in the risk assessment of chemicals in the context of the Water Framework Directive (Lepper 2005). Lemna is a small, floating, non-sediment-rooted monocotyledon with a short generation time and is rather atypical in growth form and traits compared with many other aquatic macrophytes; therefore, concerns have arisen that risk assessments based on Lemna and its endpoints may not be protective of other macrophyte species due to potential differences in exposure route, recovery rate, or sensitivity to chemicals with specific toxic modes of action (Brock et al. 2000; Hanson and Arts 2007; Vervliet-Scheebaum et al. 2006).

In January 2008, 41 macrophyte experts from academia, regulatory authorities, and business from Europe and North America discussed the current state and potential options for refinement of aquatic macrophyte risk assessment procedures at the workshop "Aquatic Macrophyte Risk Assessment for Pesticides" (AMRAP), which was organized under the auspices of SETAC-Europe (Society of Environmental Toxicology and Chemistry). During the workshop, an overview of the current European regulatory framework for the risk assessment of aquatic macrophytes was discussed, and the uncertainties and areas for improvement within the regulatory framework were identified. Conclusions and recommendations of the AMRAP workshop have been published (Maltby et al. 2010). Four working groups evolved from the workshop and were charged with the following tasks:

1. Developing and testing a proposal for a modified aquatic macrophyte Tier 1 Risk Assessment scheme for Plant Protection Products in the EU, including criteria when an additional macrophyte must be tested (Fig. 1);

2. Drafting and testing a protocol for a laboratory toxicity test with Myriophyllum spp. (Myriophyllum spicatum and Myriophyllum aquaticum) to be ring-tested in 2010;

3. Compiling an overview of laboratory toxicity methods for testing aquatic macrophytes other than Lemna;

4. Compiling data and developing guidance for the use of species sensitivity distributions (SSDs) in aquatic macrophyte risk assessment.

A SETAC Advisory Group on aquatic macrophytes was considered to be the optimal platform to facilitate the ongoing discussions regarding these tasks; the future dissemination of results of these working groups; and to provide a forum for participation by all those interested in these matters. In general, SETAC Advisory Groups have been and still are successful as a scientific forum (see as an example of another recently established SETAC Advisory Group: Preuss et al. 2009). In addition, an Advisory Group on aquatic macrophytes allows the original scope of AMRAP on the registration of plant protection products in Europe to be extended to other risk assessment schemes and legislative backgrounds in other countries (e.g., the Water Framework Directive; USA Clean Water Act).

\section{Aim and scope of the new Advisory Group}

The SETAC Advisory Group in Aquatic Macrophyte Ecotoxicology (AMEG) was established in June 2009 to provide scientifically based guidance in all aspects of chemical risk assessments for aquatic macrophyte testing across an array of test conditions including laboratory, outdoor semi-controlled and actual field conditions. The group will serve as a forum for communication, discussion, and collaboration among scientists from academia, business, and government. Within AMEG, aquatic macrophytes are considered to be all freshwater higher plants including free-floating, rooted floating-leaved, submerged and emerged forms (including hydrophytes, amphiphytes, and helophytes), in addition to freshwater macro-algae like 
Fig. 1 Proposed decision scheme for aquatic macrophytes (modified from Maltby et al. (2010)) (PGR=Plant Growth Regulator; $\mathrm{EC}=$ Effect Concentration; $\mathrm{PEC}=$ Predicted Environmental Concentration)

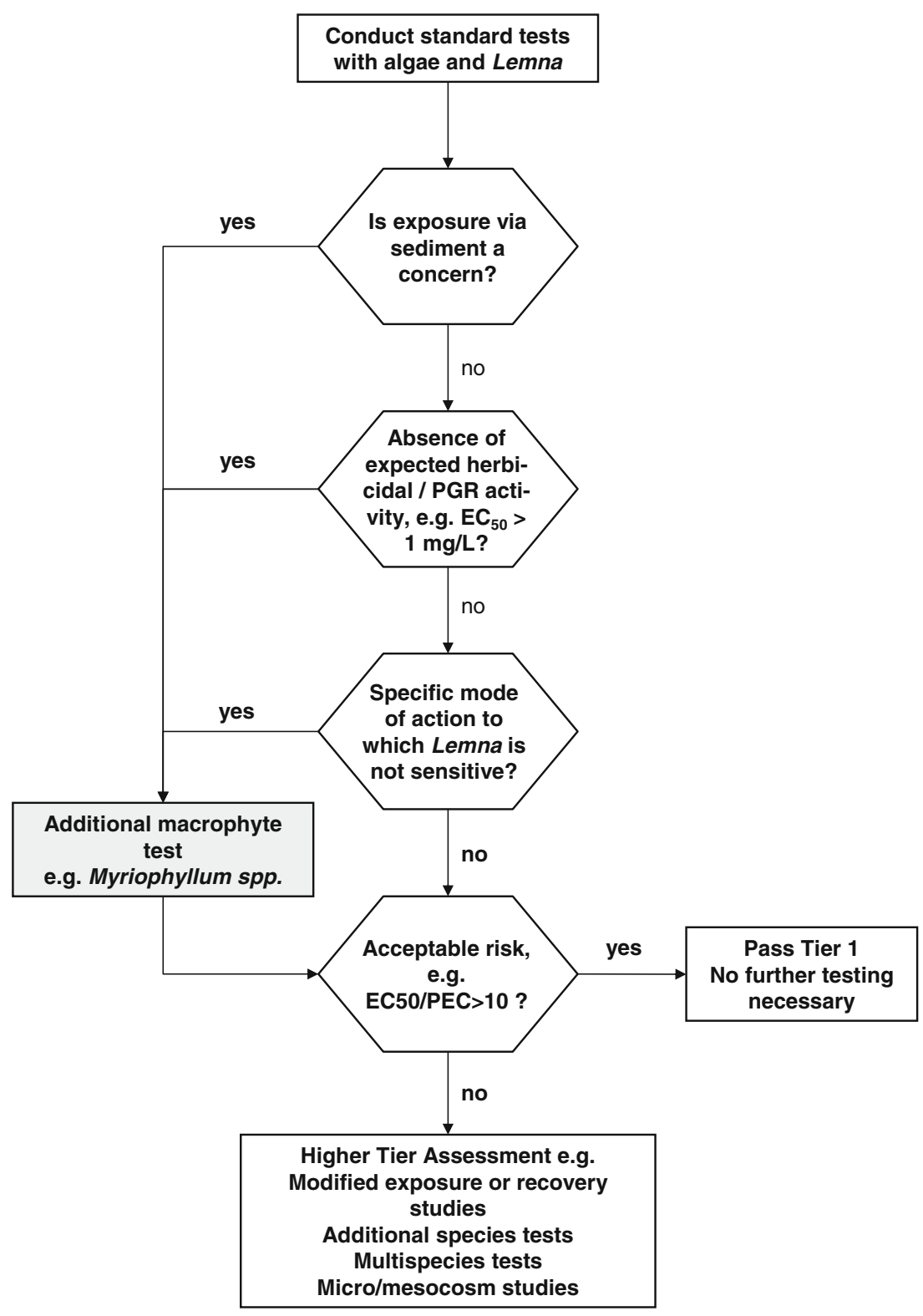

Chara, salt-water plants like sea-grasses, and salt-water macro-algae like brown algae.

The objectives of AMEG are related to three areas:

1. Development of science for the benefit of aquatic macrophyte risk assessments including:

- Monitoring, co-ordinating, and communicating the ongoing follow-up activities of the AMRAP workshop;

- Aquatic macrophyte testing for registration of plant protection products, biocides, and chemicals in general (e.g., EU, US, and Canadian directives); and

- incorporation of aquatic macrophytes more fully in retrospective risk assessment (e.g., European Water Framework Directive and USA Clean Water Act);
2. Development of guidance and tools for aquatic macrophyte risk assessment in support of current and future legislation, e.g., for the revision of the guidance documents that support the risk assessment of plant protection products in the EU; and

3. Support communication and education to build and extend a global network of macrophyte experts from academia, government, and business entities for various needs including:

- Provision of an overview of ongoing activities and new initiatives in the subject area via the SETAC website and an email distribution list;

- Organization of sessions (e.g., platform or poster) and short courses at SETAC and other society and scientific meetings; and 
- Organization and active participation in expert workshops related to risk assessments with aquatic macrophytes.

Short-term deliverables resulting from the AMRAP's activities include a ring-tested protocol for Myriophyllum spp.; recommendations for aquatic macrophyte species and aquatic macrophyte testing other than Lemna spp.; and development of a proposal for use of SSDs with aquatic macrophytes as a tool for the purpose of refined higher-tier risk assessments. Topics for long-term activities of AMEG may include the conduct and evaluation of mesocosm studies with macrophytes in order to provide guidance on the use of macrophytes in field experiments; the validation of laboratory tests performed with floating, submerged, and emergent macrophytes; the assessment of macrophyte recovery in laboratory and mesocosm tests as an endpoint within the risk assessment process; comparison of laboratory to mesocosm data to environmental monitoring data; retrospective analysis of aquatic macrophyte risk assessments in the context of the WFD and the Clean Water Act; the use of aquatic macrophytes for bioremediation and their restoration in impacted habitats; and the sustainable management of aquatic macrophytes in the context of the global spread of exotic and invasive species.

\section{Organization and contact}

The idea of a global SETAC advisory group on Aquatic Macrophyte Ecotoxicology developed after the AMRAP workshop. A number of AMRAP participants formulated a proposal that was approved by the SETAC World Council in June 2009 in order to start this advisory group. The steering committee of AMEG consists of 12 scientists from Europe and North America representing academia, business, and government (see list of authors). The first AMEG meeting was open to all participants interested in aquatic ecotoxicology and was held in Gothenburg during the SETAC EU meeting in May 2009. Over 40 scientists used this opportunity to learn about the background and the objectives of AMEG including the proposal and discussion of plans for a ring-test with Myriophyllum in a laboratory-based water-sediment test system.

The Advisory Group invites all interested scientists and students to become active in AMEG. The next meeting of the group will be held during the SETAC-Europe Annual Meeting planned for May 23-27, 2010, in Seville, Spain, where AMEG is organizing a poster-session on the use of aquatic macrophytes in ecological risk assessment. In addition, the objectives and plans of AMEG were introduced during the SETAC Laurentian Chapter meeting in Ottawa,
Canada (June 2009), the SETAC German Language branch in Freising-Weihenstephan, Germany (October 2009), and the SETAC North America Meeting in New Orleans USA (November 2009). A further presentation is planned during the SETAC Asia-Pacific Joint Conference in Vietnam, March 2010.

More information can be found on the SETAC web site (http://www.setac.org/node/363).

Open Access This article is distributed under the terms of the Creative Commons Attribution Noncommercial License which permits any noncommercial use, distribution, and reproduction in any medium, provided the original author(s) and source are credited.

\section{References}

Brock TCM, Lahr J, Van den Brink PJ (2000) Ecological risks of pesticides in freshwater ecosystems, Part I: Herbicides. AlterraRapport 088, Wageningen, Alterra, Green World Research, The Netherlands

EC (1997) Commission proposal for a council directive establishing Annex VI to Directive 91/414/EEC concerning the placing of Plant Protection Products on the market. Off J Eur Comm C 240:1-23

EC (2002) Guidance Document on Aquatic Ecotoxicology in the context of Directive 91/414/EEC. Sanco/3268/2001 rev 4 (final). European Commission Health \& Consumer Protection Directorate-General, Brussels, Belgium

EC (2009) Regulation No 1107/2009 of the European Parliament and of the Council of 21 October 2009 concerning the placing of plant protection products on the market and repealing Council Directives 79/117/EEC and 91/414/EEC. Off J Eur Union L 309:1-50

Hanson ML, Arts GHP (2007) Improving regulatory risk assessmentusing aquatic macrophytes. In: Chapman PM (ed) Learned discourses. Integrated Environmental Assessment and Management 3:466-467

Lepper P (2005) Manual on the methodological framework to derive environmental quality standards for priority substances in accordance with Article 16 of the Water Framework Directive (2000/60/EC). Fraunhofer-Institute for Molecular Biology and Applied Ecology, Schmallenberg, Germany

Maltby L, Arnold D, Arts G, Davies J, Heimbach F, Pickl C, Poulsen $\mathrm{V}$ (2010) Aquatic macrophyte risk assessment for pesticides. SETAC Europe Workshop AMRAP, Wageningen, Netherlands, pp 135. SETAC Press \& CRC Press, Taylor \& Francis Group, Boca Raton, London, New York

Preuss TG, Hommen U, Alix A, Ashauer R, Van den Brink P, Chapman P, Ducrot V, Forbes V, Grimm V, Schäfer D, Streissl F, Thorbek P (2009) Mechanistic effect models for ecological risk assessment of chemicals (MEMoRisk)-a new SETAC-Europe Advisory Group. Environ Sci Pollut Res 16:250-252

Vervliet-Scheebaum M, Knauer K, Maund SJ, Grade R, Wagner E (2006) Evaluating the necessity of additional plant testing by comparing the sensitivities of different species. Hydrobiologia 570:231-236

Wetzel RG (2001) Limnology: lake and river ecosystems. Monograph3rd ed. Academic, New York, p 1006 